\title{
Some aspects of phytohormonal participation in the control of cambial activity and xylogenesis in tree stems
}

\section{S. Lachaud}

Laboratoire de Biologie et de Physiologie Végétale (URA81), Station Biologique de Beau-Site, 25, rue du Faubourg St-Cyprien, 86000 Poitiers, France

\section{Introduction}

Early investigations concerning the regulatory role of phytohormones in cambial activity were based on the assumption that a clear correlation exists between hormonal level and response. More recently, precise measurements of endogenous hormone levels using rigorous techniques have often shown the importance of phytohormonal intervention being challenged rather than elucidating how these substances might actually regulate cambial growth. This paper, which summarizes a review in preparation, refers to some recent findings and hypotheses about 3 important questions.

\section{How can auxin (IAA) regulate seasonal variations in cambial activity and xylo- genesis?}

During the period of cambial activity, the intensity of cell production and some features of the resulting wood (radial enlargement, vessel development) are often positively correlated with the auxin level in the cambial zone. Furthermore, the early- wood-latewood transition is associated in time in Abies basalmea with the largest decrease in the IAA level (Sundberg et al., 1987). However, according to these authors, the duration of the cambial activity period appears to be independent of auxin content, and the regulation of this duration is still poorly understood. During the rest period, the IAA level often remains relatively high in the cambial zone; treatment with exogenous IAA cannot then induce the resumption of cambial activity. Thus, the responsiveness of cambial cells to auxin varies with the season. Their ability to respond, marking the end of cambial rest, is recovered after exposure to chilling temperature (Riding and Little, 1984).

Does the seasonal variation in the cambial cells' sensitivity to IAA result from changes in their ability to transport auxin? Several authors have observed a decline in IAA transport in autumn, but they have different interpretations of the cause. According to Little (1981), this change occurs after the cessation of xylem production in $A$. balsamea, so it cannot account for the onset of cambial rest. Other authors describe important qualitative changes in the pattern of IAA trans- 
port. In Fagus silvatica, the IAA pulse that is typical of polar transport in active cambium (Lachaud and Bonnemain, 1982 ) is less intense in September and disappears from October to December in diffusive profiles (Fig. 1A); its progressive renewal starting in late winter can be correlated with different steps of cambial reactivation (Fig. 1B).

The search for an explanation of the variation in cambial response to IAA may yield results by paying attention to the important structural-functional changes that occur in cambial cells during the activity-dormancy transition (Riding and Little, 1984; Catesson, 1988). In October, these cells do not divide, although they are metabolically active; membrane transport proceeds then mainly by exo- and endocytosis. A renewal of endo-membranes during this period might be associated with a seasonal inactivation of auxin receptor and carrier proteins. Later on, the breaking of rest may occur when the conditions of active membrane transport are regairled.
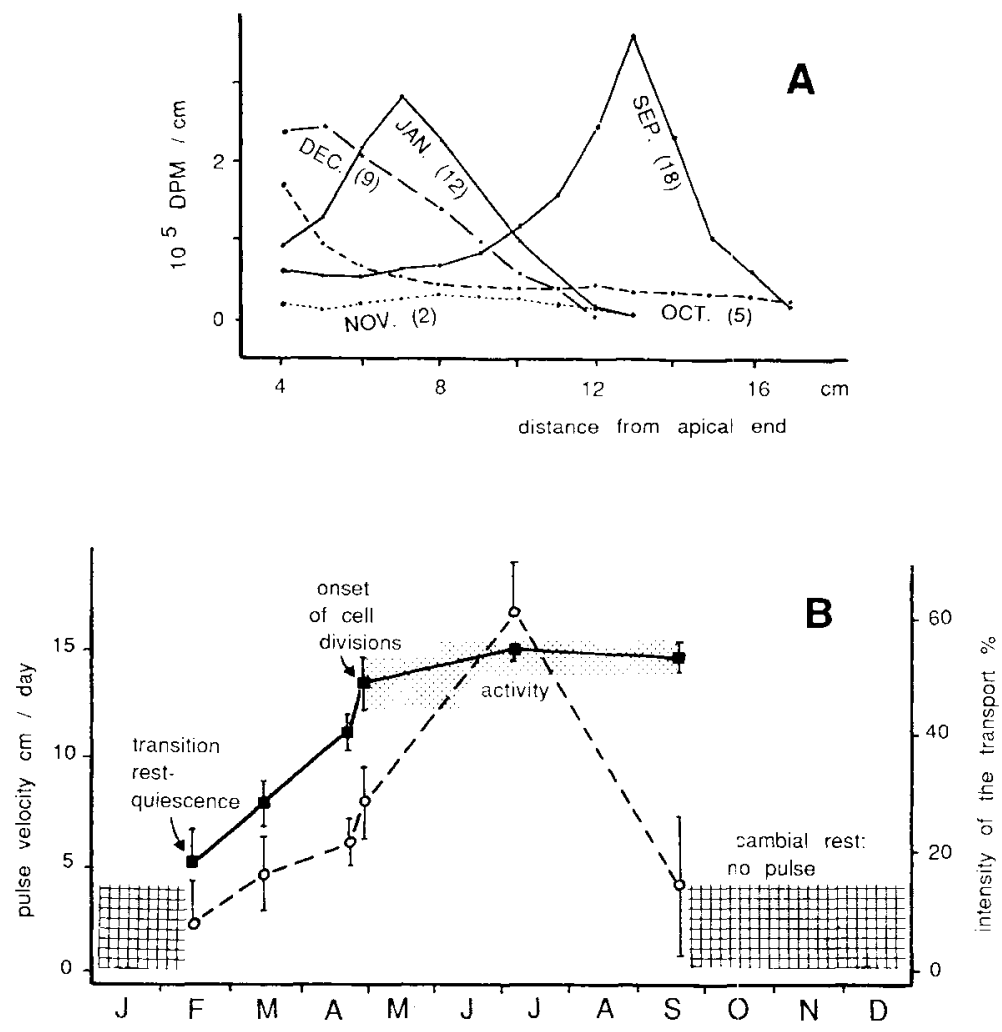

Fig. 1. Seasonal variation in the pattern of $\left[{ }^{3} \mathrm{H}\right.$ IAA transport in beech stems at $20^{\circ} \mathrm{C}$. A. Distribution of the radioactivity in cuttings after $24 \mathrm{~h}$ of transport. An agar block containing [ $\left.{ }^{3} \mathrm{H}\right] \mathrm{IAA}(185000 \mathrm{~Bq}$ or $0.25 \mathrm{nmol}$ stem) was applied to the apical section of each cutting. Values between parentheses indicate the intensity of the transport or percentage of the displaced label compared to the amount applied. B. Change in the velocity of the pulse ( $\square$ ) and in the intensity of the transport (0) throughout the year. Quantity of [ $\left.{ }^{3} \mathrm{H}\right] \mathrm{IAA}$ applied: $148000 \mathrm{~Bq}$ or $0.2 \mathrm{nmol}$ stem; average of 4-12 stems \pm SE. 
Is abscisic acid (ABA) involved in the regulation of cambial activity and xylogenesis during the annual cycle?

Exogenous ABA can reduce wood production and radial enlargement of tracheids in conifers, particularly at the end of summer. Latewood differentiation and the cessation of cambial activity have often been attributed to a high endogenous ABA level in the cambial zone. However, recent measurements (Little and Wareing, 1981) show that $A B A$ peaking in late summer is rather incidental and drought-induced. During winter, a decrease in the $A B A$ level, often associated with an increase in conjugated $A B A$, is frequently reported, but these changes are not clearly correlated with the breaking of cambial dormancy (Little and Wareing, 1981). Moreover, ABA content increases again in reactivating cambium, for example, in the trunk of Pinus contorta (Savidge and Wareing, 1984), and in young elongating shoots. In actively growing and well-watered stems, the cell sensitivity to this inhibitor seems to be low (Powell, 1982). Moreover, ABA mainly appears to enhance stress adaptation rather than to regulate active growth. Because its participation in the control of the seasonal variation in cambial activity cannot be explained by simple concentration changes, the role of $A B A$ in this process remains questionable. Recent data suggest that $A B A$ may reach its target sites if it leaks out of the most alkaline cell compartments, but its possible receptors are unknown in the cambial zone.

Is the formation of tension wood, on the upper side of leaning dicot stems, induced by an asymmetrical lateral distribution of phytohormones?

This particular xylogenesis, characterized by the differentiation of numerous gelati- nous and poorly lignified fibers and of a few small vessels, is mainly attributed to the presence of a lateral gradient in auxin concentration, auxin transport occurring preferentially towards the lower half of the bent stem. This hypothesis is supported by experiments showing that exogenous IAA induces or suppresses tension wood formation, when applied to the lower and upper sides of an inclined stem, respectively. Reports concerning the intervention of other phytohormones in this process are somewhat conflicting.

Several observations indicate that tension wood induction is a complex process. The response to gravity, in terms of lateral auxin transport and tension wood formation, is much more important in intact trees than in isolated branches (Lachaud, 1987). Is tension wood formation mediated mainly by asymmetrical auxin distribution or by changes in cell properties on both sides of the bent stem? Recent experiments indicate that proton efflux is enhanced on the lower side of leaning herbaceous stems. At the same time, calcium ions enter the cytoplasm by opening channels, which might then activate IAA carriers (Pickard, 1985). A new approach to answering the question of tension wood formation may result from these findings.

\section{Conclusion}

The recent evolution of the phytohormone concept and the considerable progress realized in cytophysiology and biochemistry prompt the following remarks about the regulation of cambial dynamics: 1) the properties of cambial cells, particularly the pattern of membrane transport, may change during the annual growth cycle of the tree; 2) the sensitivity of cambial cells to a phytohormone may be low if the regulator is compartmentalized or if its 
receptors are seasonally missing or modified; 3) in an active cambial cell, phytohormones may regulate the intensity of sink activity rather than its duration.

\section{References}

Catesson A.M. (1988) Cambial cytology and biochemistry. In: Radial Growth of Plants. (lqbal M., ed.), Research Studies Press, Taunton, U.K., in press

Lachaud S. (1987) Xylogenèse chez les dicotylédones arborescentes. V. Formation du bois de tension et transport de l'acide indole acétique tritié chez le hêtre. Can. J. Bot. 65, 1253-1258

Lachaud S. \& Bonnemain J.L. (1982) Xylogenèse chez les dicotylédones arborescentes. III. Transport de l'auxine et activité cambiale dans les jeunes tiges de hêtre. Can. J. Bot. 60, 869876

Little C.H.A. (1981) Effect of cambial dormancy state on the transport of $\left[1{ }^{14} \mathrm{C}\right]$ indol-3-ylacetic acid in Abies balsamea shoots. Can. J. Bot. 59, 342-348
Little C.H.A. \& Wareing P.F. (1981) Control of cambial activity and dormancy in Picea sitchensis by indol-3-ylacetic and abscisic acids. Can. J. Bot. 59, 1480-1493

Pickard B.G. (19:85) Early events in geotropism of seedling shocits. Annu. Rev. Plant Physiol. $36,55-75$

Powell L.E. (1982) Shoot growth in woody plants and possible participation of abscisic acid. In: Plant Growth Substances. (Wareing P.F., ed.), Academic Press, New York, pp. 363372

Riding R.T. \& Little C.H.A. (1984) Anatomy and histochemistry of Abies balsamea cambial zone cells during the onset and breaking of dormancy. Can. J. Bot. 62, 2570-2579

Savidge R.A. \& Wareing P.F. (1984) Seasonal cambial activity and xylem development in Pinus contorta in relation to endogenous indol3-yl-acetic and (S)-abscisic acid levels. Can. J. For. Res. 14, 676-682

Sundberg B., Little C.H.A, Riding R.T. \& Sandberg G. (1987) Levels of endogenous indole-3acetic acid in the vascular cambium region of Abies balsamea trees during the activityrest-quiescence transition. Physiol. Plant. 71, $163-170$ 